\title{
The colloidal tool-box approach for fuel cell catalysts: Systematic study of perfluorosulfonate-ionomer impregnation and Pt loading
}

\author{
Jozsef Speder ${ }^{\mathrm{a}}$, Alessandro Zana ${ }^{\mathrm{a}}$ and Matthias Arenz ${ }^{\mathrm{a} *}$ \\ a Nano-Science Center, Department of Chemistry, University of Copenhagen, \\ Universitetsparken 5, DK-2100 Copenhagen Ø, Denmark \\ *corresponding author: m.arenz@chem.ku.dk
}

\begin{abstract}
In this study the correlation between the impregnation of proton exchange membrane fuel cell catalysts with perfluorosulfonate-ionomer (PFSI) and its electrochemical and electrocatalytic properties is investigated for different Pt loadings and carbon supports using a rotating-disk electrode (RDE) setup. We concentrate on its influence on the electrochemical surface area (ECSA) and the oxygen reduction reaction (ORR) activity. For this purpose platinum (Pt) nanoparticles are prepared via a colloidal based preparation route and supported on three different carbon supports. Based on RDE experiments, we show that the ionomer has an influence both on the Pt utilization and the apparent kinetic current density of ORR. The experimental data reveal a strong interaction in the microstructure between the electrochemical properties and the surface properties of the carbon supports, metal loading and ionomer content. This study demonstrates that the colloidal synthesis approach offers interesting potential for systematic studies for the optimization of fuel cell catalysts.
\end{abstract}

\section{Keywords}

Polymer electrolyte membrane fuel cells; Cathode catalyst layer; Catalyst supports; Ionomer content; Oxygen reduction reaction 


\section{Introduction}

Polymer electrolyte membrane fuel cells (PEMFCs) are the leading candidates for energy converters in a hydrogen based economy. PEMFCs are already in use in various mobile applications, including the transport industry to convert the chemical energy stored in hydrogen to electric energy by combining high efficiency and no or very low emissions. However, the large-scale commercialization of PEMFCs still faces some challenges, e.g. the high cost and low abundance of platinum, which is used for catalyzing the chemical reactions, requires further improvements in the metal utilization.

Optimizing the catalyst in membrane electrode assemblies (MEAs) involves a better understanding of Pt utilization at the triple-phase boundary in the catalyst layer, where the reactant, the ionic conducting polymer, and the electronic conducting substrate are present on the same platinum $(\mathrm{Pt})$ or Pt-alloy nanoparticle (NP) [1]. Pt can only be utilized in the electrochemical reactions when it is in contact with both the membrane electrolyte and the support and at the same time accessible for the reactant gas and water to and from the reaction sites. Therefore the increase in the number of such active sites and the platinum utilization efficiency are essential for the enhancement of the cell performance. The challenge is to activate $\mathrm{Pt}$ as catalyst and to improve the catalytic performance by covering/impregnating the Pt NPs by a thin layer of ionomer film and at the same time to maintain their accessibility for the fuel gas and transport of water. The best cell performance is always achieved with an optimal balance between catalytic activity and maximum $\mathrm{Pt}$ utilization, proton conductivity, and oxygen transport [2].

Among the different ionomers available for PEMFC applications, perfluorosulfonate type ionomers (PFSI), such as Nafion by DuPont, are the most widely used. Several studies concentrate on producing high-quality catalyst layers by using an optimal amount of Nafion (in $\mathrm{mg} \mathrm{cm}^{-2}$ or wt.\%) [3-7]. Adding Nafion to the catalyst layer, first the ionomer fills up the 
pores of the catalyst layer. While macropores can be filled completely, it is difficult to fill the micropores [8]. Further addition of ionomer results in a formation of films on the surface of the electrode (pores are reported to be completely filled in the range from 0.8 to $1.0 \mathrm{mg}$ of Nafion $/ \mathrm{cm}^{2}$ of electrode). As the ionic resistance of this film is higher than the Nafion membrane, this increases the overall ionic resistance of the electrode [9-12]. Furthermore, since the ionic conductivity of the ionomer is high for protons, but its electric conductivity is very low, a surplus addition of ionomer leads to an increase in proton conductivity at the expense of electronic conductivity. Excessive ionomer may block the gas channels limiting oxygen transport and therefore the original interface is transformed from a three-phase (reactants-electrolyte-catalyst) to a two-phase (electrolyte-catalyst) boundary; especially at a high current density $[3,13]$. To balance both of these antagonist effects, often a compromise of ca. 25-30 wt. \% Nafion, depending on the preparation route, is used in the catalyst layer in MEA studies [4, 9, 13-15].

So far only limited studies exist that tackle the optimization of the ionomer content in catalyst inks using a thin film rotating disk electrode (RDE) approach $[16,17]$. This may in part due to the fact that in thin film RDE studies the aqueous electrolyte is available for proton transport and its wetting and pore filling properties are different than the ones from the ionomer. Thus protonic transport should not be a limiting faction and the results cannot be directly transferred to MEA performance (as cannot activity data obtained from thin film RDE studies in aqueous electrolytes). In this study, we present an extremely easy method to prepare carbon supported Pt NP based PEMFC catalysts containing Nafion ionomer. No acid or heat treatment is used, which renders the catalyst layer difficult to control. In contrast to traditional synthesis methods, where Pt NPs are deposited within the porous carbon nanostructure and may be inaccessible for the polymer electrolyte, here the Pt NPs are prepared separately and concomitantly supported on high surface area (HSA) carbon black 
supports. Thus different catalysts are prepared using the same stock solution of Pt NPs, but various commercially available carbon materials. This "tool-box" approach has been used before in various applications [18-23]; the new element of the present study is that also Nafion was directly introduced in the synthesis procedure allowing us to systematically investigate the influence of Nafion impregnation on the Pt utilization and oxygen reduction reaction (ORR) activity. The electrochemical properties of the investigated catalysts are characterized in RDE measurements using the thin film approach [24, 25]. In order to ensure sufficient $\mathrm{O}_{2}$ diffusion to the Pt NP surfaces, we applied an ultra-thin and uniform dispersion of the Pt/C catalyst on the glassy carbon (GC) disk [26-28]. We show that the properties of the applied carbon supports have a paramount importance in determining the ideal amount of Nafion for optimizing the electrode active area in aqueous conditions and to enhance the surface area specific ORR activity as well as the apparent mass activity (MA).

\section{Experimental Section}

\subsection{Catalyst material synthesis}

The investigated catalysts, hereafter called $\mathrm{Pt} / \mathrm{C}$, were synthesized in-house according to Refs.[18, 29]. The synthesis of the electrocatalysts consists of two main steps. First, a suspension of colloidal Pt NPs with narrow size distribution is prepared via an ethylene glycol (EG) route. Then the NPs are deposited in varying amounts onto the HSA carbon support, i.e. Ketjenblack EC-300J and EC-600JD (AkzoNobel, total Brunauer-Emmett-Teller (BET) surface area: $795 \mathrm{~m}^{2} \mathrm{~g}^{-1}$ and $1400 \mathrm{~m}^{2} \mathrm{~g}^{-1}$ ) or Vulcan XC72R (Cabot Corporation, BET area: $235 \mathrm{~m}^{2} \mathrm{~g}^{-1}$ ). A detailed description of the catalyst preparation can be found in Ref.[29]. Briefly, a colloidal suspension of Pt NPs is synthesized by mixing an ethylene glycol solution of $\mathrm{NaOH}(50 \mathrm{ml}, 0.4 \mathrm{M})$ with an ethylene glycol solution of $\mathrm{H}_{2} \mathrm{PtCl}_{6} \cdot \mathrm{xH}_{2} \mathrm{O}(50 \mathrm{ml}, 1.0 \mathrm{~g})$ under vigorous stirring resulting in a yellowish platinum hydroxide or oxide colloidal 
solution. The reaction is performed under an inert atmosphere of Ar. The colloidal solution is then heated to $160^{\circ} \mathrm{C}$ while purging Ar gas through the system for $3 \mathrm{~h}$ obtaining a blackishbrown homogeneous metal particle colloidal suspension with a Pt concentration of $4 \mathrm{~g}_{\mathrm{Pt}} / \mathrm{l}_{\mathrm{EG}}$. The average diameter of the obtained Pt NPs is typically around $2 \mathrm{~nm}$ exhibiting a narrow size distribution. In order to support the Pt NPs onto a HSA carbon $1 \mathrm{M} \mathrm{HCl}$ was added to the colloidal NP solution in a ratio of ca. 2:1 ( $\mathrm{HCl} / \mathrm{NP}$ solution) for precipitation. The solution was centrifuged (4000 rpm, $6 \mathrm{~min}$ ) and the supernatant solvent discarded. This procedure was repeated before re-dispersing the NPs in acetone. Finally, the as-synthesized Pt NPs were deposited onto different HSA carbons by mixing the NPs suspension (in acetone) with carbon black mixed in $3 \mathrm{~mL}$ of acetone and sonicating for $1 \mathrm{~h}$. Finally the catalyst was dried.

$\mathrm{Pt} / \mathrm{C}$ samples were prepared with different nominal Pt loadings between 10 and $80 \mathrm{wt} . \% \mathrm{Pt}$ on Ketjenblack EC-300J and with 30 and 70 wt.\% on Ketjenblack EC-600JD and Vulcan XC72R. The actual Pt content of the catalysts was analyzed by ICP-MS (NexION 300X, Perkin Elmer) through a Meinhard quartz nebulizer and a cyclonic spray chamber, operating at nebulizer gas flow rates of between 1-1.02 1/min (Ar, purity 5.0). Before ICP analysis, the catalysts were dissolved in aqua regia (the volume ratio of $\mathrm{HCl}$ to $\mathrm{HNO}_{3}$ was 3:1) and then diluted. The nominal and the actual Pt loading values agreed within ca. 10-30\%. As a general trend the difference decreased with higher loadings and typical values are around $10 \%$. For the calculation of the electrochemically accessible surface area (ECSA) and the mass activities the actual Pt loading values were used instead of the nominal ones. However for simplicity reasons the catalysts are always addressed according to their nominal Pt loading. In order to test the influence of ionomer impregnation on the ORR activity, PFSI can be added to the carbon support or to the Pt NPs suspension [18]. Here the latter option was used as this led to better catalyst performance. That is, Nafion ${ }^{\circledR}$ dissolved in acetone was mixed with the EG-free Pt NP suspension before mixing everything with the carbon support. The 
ionomer content of the catalysts was varied between 10 and $45 \mathrm{wt} . \%$. The weight percentage of Nafion ${ }^{\circledR}$ ionomer in the catalyst is thereby defined as follows:

$$
\text { Nafion content (wt. \%) }=\frac{M_{\text {Nafion }}}{M_{\text {Nafion }}+M_{\text {Carbon }}+M_{P t}} X 100 \%
$$

where $M_{\text {Nafion }}$ is the weight of the dry ionomer and $M_{\text {Carbon, }} M_{P t}$ are the weights of carbon and platinum in the catalyst, respectively.

\subsection{Electrochemical Characterization}

The electrochemical measurements were performed using a computer controlled, home-built potentiostat and a rotating disk electrode (RDE) setup. The electrochemical cell was a homebuilt Teflon cell based on a three-compartment configuration [30, 31]. The counter (auxiliary) electrode was a platinum mesh, the reference electrode a Schott $\mathrm{Ag} / \mathrm{AgCl} / \mathrm{KCl}$ (sat) electrode placed in a separated compartment separated by an additional Nafion ${ }^{\circledR}$ membrane in order to avoid the diffusion of $\mathrm{Cl}^{-}$ions into the main compartment [32]. All potentials in this work are referred to the reversible hydrogen electrode (RHE) potential, which was experimentally determined for each measurement series. All electrolyte solutions were prepared with Millipore ${ }^{\circledR}$ water $(>18.3 \mathrm{M} \Omega \mathrm{cm}, \mathrm{TOC}<5 \mathrm{ppb}) . \mathrm{HClO}_{4}$ and $\mathrm{HCl}$ were from Merck (Suprapur grade). The measurements were performed at $20^{\circ} \mathrm{C}$. Prior to the $\mathrm{RDE}$ measurements the glassy carbon (GC) working electrode $\left(5 \mathrm{~mm}\right.$ diameter, $0.196 \mathrm{~cm}^{2}$ geometrical surface area) was polished to mirror finish using alumina oxide paste 0.3 and $0.05 \mu \mathrm{m}$ (Buelher-Met, deagglomerated $\alpha$-alumina and $\gamma$-alumina, respectively), and cleaned ultrasonically in ultrapure water and cc. $70 \% \mathrm{HClO}_{4}$. The catalyst ink was prepared by ultrasonically dispersing the catalyst powder in ultrapure water $\left(0.14 \mathrm{mg}_{\mathrm{Pt}} \mathrm{cm}^{-3}\right)$. A volume of $20 \mu \mathrm{L}$ of the suspension was then pipetted onto the GC electrode leading to a $\mathrm{Pt}$ 
loading of $14 \mu \mathrm{g}_{\mathrm{Pt}} \mathrm{cm}^{-2}$ and thereafter dried in a nitrogen gas stream. Several different GC tips were prepared and only samples with a uniform catalyst film (after an optical control) were analyzed. All electrochemical experiments were performed in $0.1 \mathrm{M} \mathrm{HClO}_{4}$ solution and at least three times repeated. Prior to the measurements the electrolyte was de-aerated by purging with Ar gas (99.998\%, Air Liquide), and the measurements were started with cleaning the catalyst by potential cycles between 0.05 and $1.1 \mathrm{~V}_{\mathrm{RHE}}$ at a scan rate of 50 $\mathrm{mVs}^{-1}$. The specific activity (SA) of the ORR was determined from the positive going RDE polarization curves recorded in $\mathrm{O}_{2}$ saturated $0.1 \mathrm{M} \mathrm{HClO}_{4}$ solution at a scan rate of $50 \mathrm{mV} \mathrm{s}{ }^{-}$ ${ }^{1}$ and at a rotation speed of $1600 \mathrm{rpm}$. In order to exclusively analyze the ORR current, the polarization curves were corrected for the non-faradaic background by subtracting the cyclic voltammograms (CVs) recorded in Ar-purged electrolyte. Furthermore, the solution resistance between the working electrode and the Luggin capillary was determined using an AC signal $(5 \mathrm{kHz}, 5 \mathrm{mV})$ and thereafter compensated for using the potentiostat's analog positive feedback scheme. The resulting effective solution resistance was less than $3 \Omega$ for each experiment. The ECSA of the catalysts was determined from the CO stripping charge [33] recorded at a sweep rate of $50 \mathrm{mV} \mathrm{s}^{-1}$. The MA was calculated based on the SA and the ECSA [34]. For the interested reader, we refer to the following references concerning the method of thin film RDE measurements [28, 35].

\subsection{Physical characterization of the Pt catalysts (BET-measurements)}

Gas (nitrogen) adsorption isotherms were recorded using a Quantochrome Autosorb-1 Sorption Analyser in the relative pressure range $10^{-6}$ to $0.995 \mathrm{P} / \mathrm{P}_{0}$ at liquid nitrogen temperature (77K). Prior to experiments, the samples were degassed by heating to $200^{\circ} \mathrm{C}$ in vacuum $\left(<10^{-3}\right.$ torr $)$ for 24 hours. The surface area was determined in the relative pressure range $0.05<\mathrm{P} / \mathrm{P}_{0}<0.3$ using the $\mathrm{BET}$ equation [36]. For all samples the BET plots were linear in the relative pressure range examined and the BET constant $>50$ confirming the 
applicability of the BET equation. Pore sizes were estimated using t-plots.

\section{Results and Discussion}

\subsection{Carbon blacks as support materials}

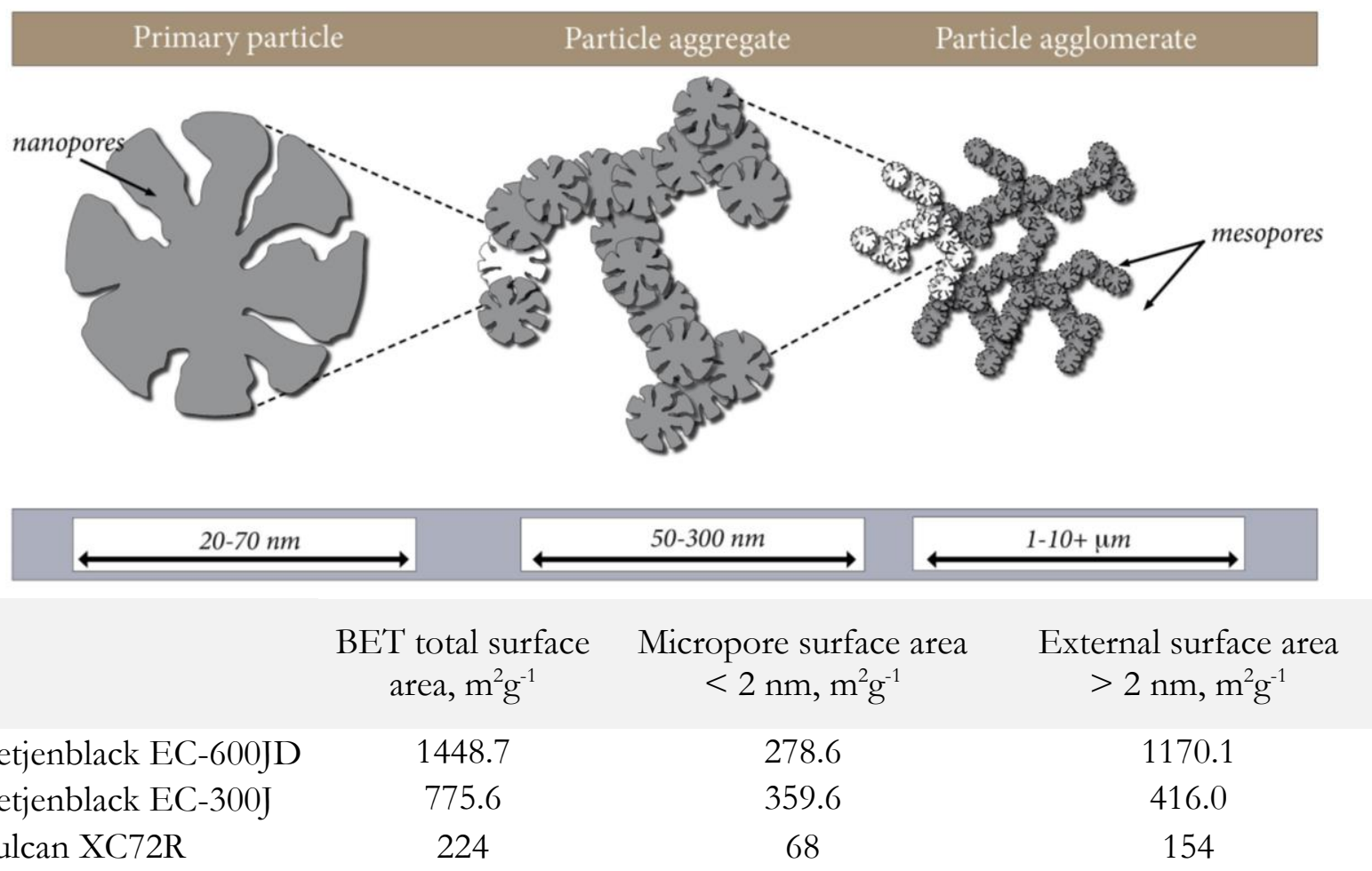

Fig. 1. Schematic sketch of the carbon structure and their experimentally determined BET-surface area properties

We start our discussion with the description of the carbon materials used in this study. Carbon blacks with high BET surface area have been widely used as support materials for PEM fuel cell applications and are commercially available. As reported by Uchida et al., such carbon materials possess an extensive pore network and a large pore volume [37-39]. The microstructure of such carbon blacks is based on primary particles with a diameter of 20-30 nm. These primary particles build up chain-like aggregates and form structured agglomerates (50 - $100 \mathrm{~nm}$ diameter). The carbons are usually characterized by three types of pores: micropores (< ca. $2 \mathrm{~nm}$ in diameter), mesopores (from 2 to $40 \mathrm{~nm}$ in diameter) and 
macropores (> $40 \mathrm{~nm}$ ) as schematically shown in Figure 1. The micropores are considered to correspond to the voids within the primary carbon particles between the turbostratic graphite planes of the crystallites [40]. Mesopores are void spaces within the agglomerates. It should be mentioned that Uchida et al. use a slightly different classification. They define the pores from 2 to $40 \mathrm{~nm}$ to be the "primary pores" within the carbon aggregates and the pores from 40 to $100 \mathrm{~nm}$, the "secondary pores" between aggregates of carbon agglomerates [15]. However in our case, it is important to distinguish between the fraction of the microporous/internal and the external surface area that is accessible for Pt NPs.

In order to gain a better overview of the pore size distribution in the used carbons, the materials were characterized by BET-surface area measurements. This analysis is a very useful tool since it can give an estimate for the pore structure of the support materials. The BET analysis indicates that the carbons used in the present study have a total BET surface area between 235 and $1448 \mathrm{~m}^{2} \mathrm{~g}^{-1}$, in the following order: Vulcan XC72R < Ketjenblack EC$300 \mathrm{~J}<$ Ketjenblack EC-600JD, see Figure 1. A closer look at the data reveals that the Ketjenblack samples possess a larger pore volume and micropore fraction as compared to the Vulcan XC72R.

\subsection{Impact of Nafion ionomer on Pt/EC-300J catalysts}

Due to the distinctively different physical properties of the carbons one would expect a different behavior when impregnating them with Nafion ionomer. Previous studies investigating Nafion impregnation were carried out on commercial catalysts, such as samples from Tanaka TKK, Johnson Matthey HiSpec or E-TEK with in general unknown carbon supports. Futhermore, in these studies, Nafion has been added to the pre-synthesized catalysts, i.e. the catalyst powder [3-7]. Therefore it was not possible to vary the metal loading and Nafion to catalyst ratio independently and most studies are focused on only one metal loading. By contrast, the "tool-box" synthesis approach used in the present study not 
only enables the flexible change of the amount of ionomer used in the preparation of the catalyst, but the $\mathrm{Pt}$ to $\mathrm{C}$ ratio can be independently controlled as well. To our knowledge, the present study is therefore the first time it was systematically investigated how the ionomer content in a catalyst influences the Pt utilization as a function of the Pt to carbon ratio.

We start our discussion by describing the different catalyst samples prepared by using the mesoporous Ketjenblack EC-300J carbon black support without any Nafion ionomer added, see black markers and bars in Figure 2. All samples were prepared from the same mother suspension with Pt NPs of an average diameter of ca. $2 \mathrm{~nm} \mathrm{[18].} \mathrm{The} \mathrm{Pt} \mathrm{weight} \mathrm{loading} \mathrm{was}$ systematically varied between 10-80 wt.\%. The electrochemical properties of the catalyst samples are summarized in Fig. 2. The ECSA of the samples varies between roughly 60 and $80 \mathrm{~m}^{2} \mathrm{~g}^{-1} \mathrm{Pt}$, whereby at metal loadings of $70 \mathrm{wt} . \%$ or lower the ECSA stays within 75 to 80 $\mathrm{m}^{2} \mathrm{~g}^{-1} \mathrm{Pt}$. In other words Pt, NP agglomeration and a concomitant loss in ECSA could only be observed at extremely high metal loadings above $70 \mathrm{Pt} w t . \%$. The SA varies between roughly 300 and $800 \mu \mathrm{A} \mathrm{cm}^{-2} \mathrm{Pt}$ and exhibits a strong dependency on the metal loading, i.e. samples with higher Pt wt.\% are more active for the ORR. This observation has been recently investigated and reported by our group. We proposed the increase in SA with increasing Pt wt. $\%$ as a result of the so-called particle proximity effect, i.e. by lowering the interparticle distance between neighboring particles an increase in SA for ORR can be observed [20, 41]. As demonstrated in Fig. $2 \mathrm{~b}$ the oxygen reduction activity expressed in terms of $\mathrm{A} \mathrm{g}^{-1} \mathrm{Pt}$ (MA @ $0.9 \mathrm{~V}$ ), which is a better representative parameter for the economic potential of the catalysts, depends on the metal loading as well. The ORR MA increases from $245 \mathrm{~A} \mathrm{~g}^{-1} \mathrm{Pt}$ at low Pt loading to $485 \mathrm{~A} \mathrm{~g}^{-1} \mathrm{Pt}$ at high Pt loading where the increase in SA is compensated by a decrease in ECSA. Discussing the results, it should be mentioned that also the catalyst film properties on the GC can influence the observed SA [27, 42], even though in all cases regular diffusion limited currents are observed. That is, similar as in MEA optimization, in catalyst 
optimization using the thin film RDE approach, it is sometimes difficult to distinguish if an improvement in the observed performance is due to the optimization of the intrinsic catalytic properties or the catalyst film properties. In our case, changing the $\mathrm{Pt}$ to $\mathrm{C}$ ratio at constant catalyst loading on the GC, leads to thinner catalyst films and part of the SA increase could be related to this effect, see also discussion below. Studies where we keep the carbon support loading on the GC tip constant to further elucidate this effect are under preparation. On the other hand the different CVs show a shift of the reduction of oxygenated species when increasing the Pt to $\mathrm{C}$ ratio [20], which is typically associated with an increase in intrinsic ORR activity.

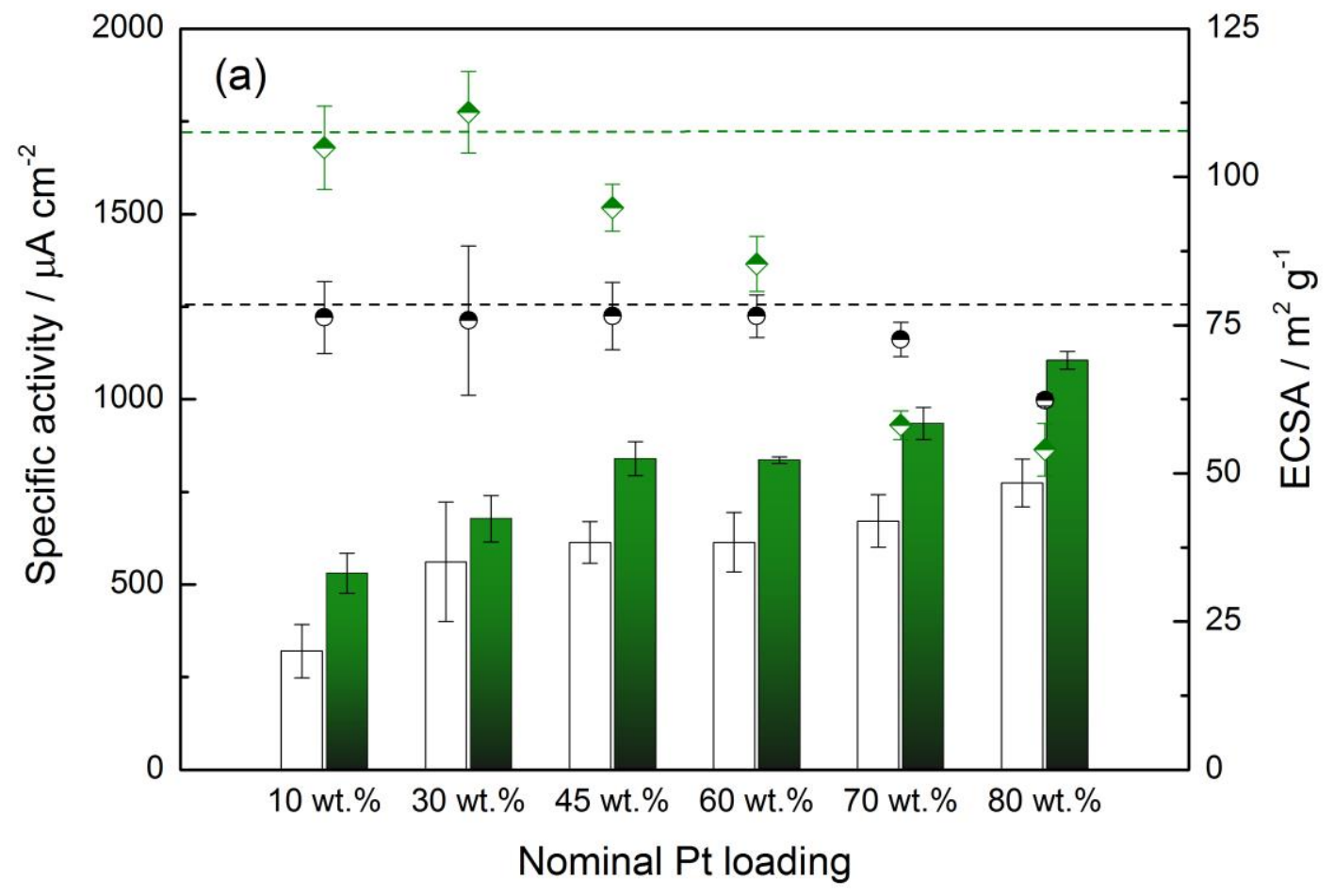




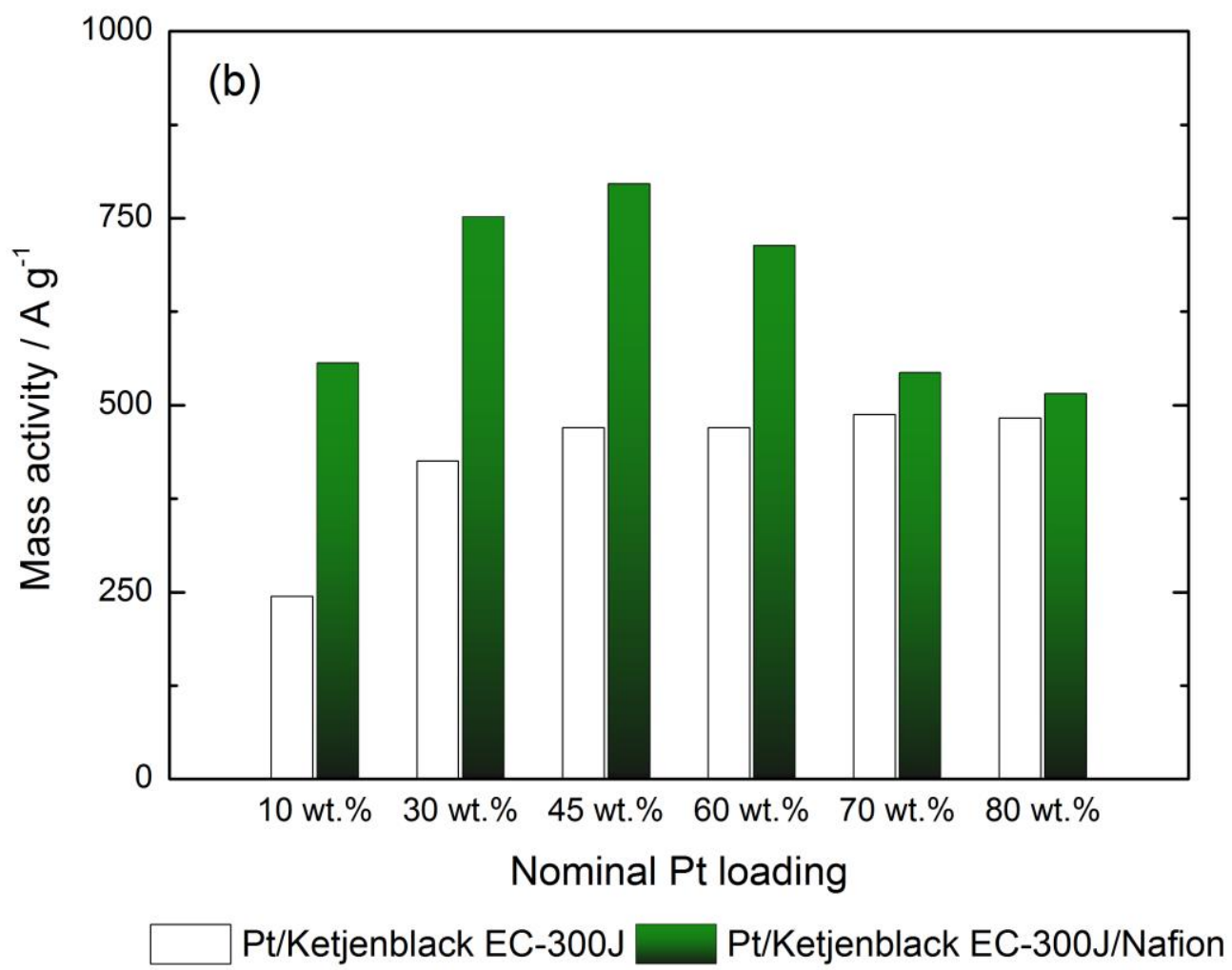

Fig. 2 Impact of ionomer impregnation on the electrochemical properties of Pt/Ketjenblack EC-300J catalysts. The black markers and bars indicate samples without Nafion, the green catalyst samples are impregnated with 28 wt.\% of Nafion. (a) ECSA (markers) and SA (bars) and (b) MA (bars) as a function of metal loadings in wt.\%.

In the next step the Pt/EC-300J samples with a nominal Pt wt.\% of 10-80 were impregnated by Nafion. PEMFCs catalyst layers in MEAs usually contain significant (from 5 to $40 \%$ ) amounts of Nafion to improve their proton conductivity and to increase the catalyst utilization [14]. To investigate how the ionomer to carbon ration influences the $\mathrm{Pt}$ utilization on the Ketjenblack EC-300J carbon black, we added a fixed amount, namely 28 wt.\%, of Nafion ionomer to the catalyst samples. This amount of ionomer is typical used in the preparation of MEAs. The introduction of the ionomer to the catalyst has several impacts on the observed electrochemical properties, see Fig. 2. It is seen that Nafion profoundly influences ECSA, i.e. the apparent dispersion of the Pt NPs on the carbon support. At low nominal Pt wt.\% the ionomer impregnation significantly increases the platinum utilization. 
As the observed effect (tested in aqueous electrolyte) should not be due to improved triplephase boundary, possible factors for this ECSA increase might be an enhancement in the Pt NP sticking and their distribution on the carbon support as well as improved film properties. At higher Pt loadings, i.e. above 45 wt. $\%$, concomitant with the decrease of the relative amount of carbon in the catalyst the ionomer decreases the ECSA. This observation therefore indicates that above a certain ionomer to carbon ratio the ionomer blocks the accessible carbon surface area and thus increases NP agglomeration or blocks the Pt surface itself [40, 43].

The Nafion content has also a significant influence on the apparent Pt surface area specific ORR turnover rates. The SA varies between 510 and $1100 \mu \mathrm{A} \mathrm{cm}{ }^{-2} \mathrm{Pt}$, which represents an improvement factor of ca. $40-50 \%$ as compared to the corresponding Nafion free cases. However, SA and ECSA improvement are not directly related to each other as might be expected from a pure optimization of the catalyst layer on the GC electrode. Correspondingly, the MA improves as well, but in a different fashion than the SA as function of Pt loading. The nominal Pt loading that corresponds to the maximum MA shifts from a higher ca. $70 \mathrm{wt} . \%$ to a lower Pt loading of $45 \mathrm{wt} . \%$. Interestingly, these observations of an activity improvement due to the addition of Nafion are in contrast to work reporting an inhibiting effect of Nafion on the ORR $[44,45]$. One of the differences between the presented work and the previous approaches using supported $\mathrm{Pt} / \mathrm{C}$ catalysts is the application of the tool-box approach. Therefore the improved performance despite ionomer addition indicates that using the tool-box approach the enhancement in Pt NP sticking and the improvement of their distribution on the carbon support and/or an improvement in film properties can overcompensate the inhibiting effect of Nafion when mixed to a $\mathrm{Pt} / \mathrm{C}$ catalyst powder or ink.

\subsection{The influence of carbon materials}


In the next step we focused on two questions: (i) how does the carbon support porosity and (ii) how does the amount of ionomer in the PEMFC catalyst influence its electrochemical properties and performance. For this purpose, we prepared for three different carbon supports (Ketjenblack EC-600JD, Ketjenblack EC-300J, and Vulcan XC72R) samples with two different Pt loadings, 30 and 70 wt.\%, and varied the ionomer content (see Table 1. for detailed information of the physical properties of the carbon supports).

As summarized in Fig. 3A, the ECSA values of the 30 wt.\% samples are between 70 and 110 $\mathrm{m}^{2} \mathrm{~g}^{-1} \mathrm{Pt}$ depending on the carbon support. Without Nafion addition, high Pt ECSA was obtained on Ketjenblack EC-600JD and Vulcan XC72R, i.e. 108 and $110 \mathrm{~m}^{2} \mathrm{~g}^{-1} \mathrm{Pt}$, but not on Ketjenblack EC-300J $\left(70 \mathrm{~m}^{2} \mathrm{~g}^{-1} \mathrm{Pt}\right)$. We propose that this observation can be explained by the chemical properties of the carbon black materials. As previously demonstrated, using a colloidal synthesis approach the number of defect sites and surface oxide groups play a key role in achieving high Pt NP dispersion $[18,46]$. Ketjenblack EC-600JD and Vulcan XC72R might have more defect sites than Ketjenblack EC-300J due to the production process from Ketjenblack EC-600JD.

Impregnation of the catalyst samples with Nafion (see Fig. 3A) has distinct effects on the ECSA depending which carbon material was used in the synthesis. While Nafion impregnation decreases the ECSA of Pt/EC-600JD and Pt/Vulcan with increasing ionomer content, Nafion impregnation causes a substantial increase in ECSA for Pt/EC-300J, i.e. from 70 to $110 \mathrm{~m}^{2} \mathrm{~g}^{-1} \mathrm{Pt}$, when increasing the Nafion content to $37 \mathrm{wt} \%$. Considering that the carbon blacks have quite different BET surface areas ranging from 235 to $1400 \mathrm{~m}^{2} \mathrm{~g}^{-1} \mathrm{C}$, it seems that no simple correlation between BET area and optimized Nafion content in the catalyst layer can be made based on our studies. 

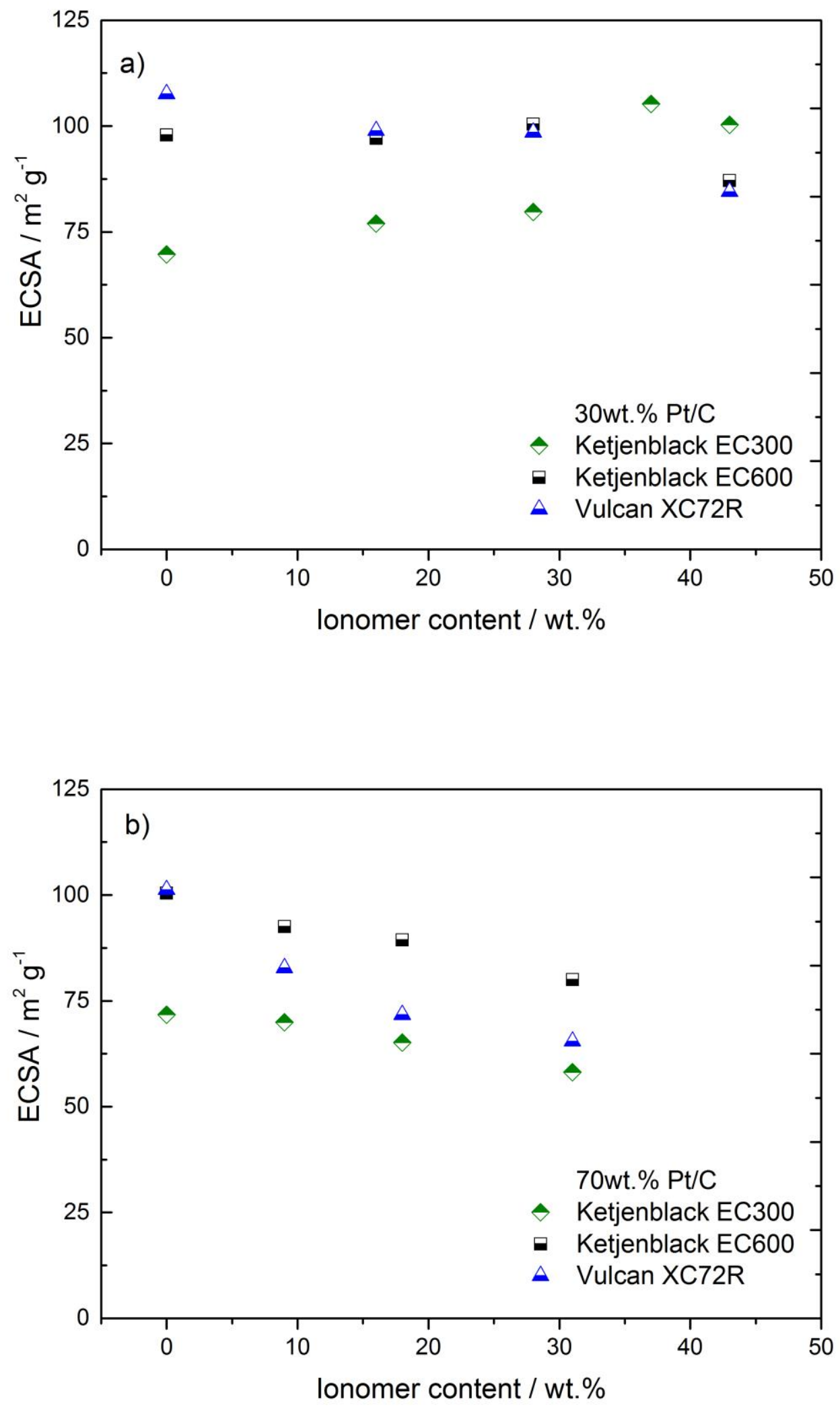

Fig. 3 ECSA of Pt/C samples measured as a function of the ionomer content (wt.\%). a) catalyst samples containing 30 wt.\% Pt loading; b) catalyst samples containing 70 wt.\% Pt loading. 
Increasing the Pt loading in the catalysts to $70 \mathrm{wt} . \%$, a different behavior is observed. Without Nafion the ECSA of the Pt/C samples ranges between 70 and $100 \mathrm{~m}^{2} \mathrm{~g}^{-1} \mathrm{Pt}$, with high values for EC-600JD and Vulcan and a lower value for EC-300J. Impregnating the catalysts with ionomer results in a loss of ECSA in all cases; that is the determined ECSA decreases with increasing ionomer content for all investigated carbon supports. This observation indicates that at such high metal loading the ionomer promotes particle agglomeration during the colloidal synthesis even at moderate ionomer content and/or that the ionomer blocks Pt sites. This finding is in line with literature data obtained on in situ synthetized Pt NPs in a Nafion matrix, where a direct correlation between the $\mathrm{Pt}$ to ionomer ratio and $\mathrm{NP}$ agglomeration was found [47, 48]. The stabilizing effect of nonionic polymers is often correlated to a coordination interaction between the nonionic polymer and the metal also referred to as a steric stabilization. Since Nafion is an ionic polymer, the electrostatic stabilization could also contribute to the stability catalyst structure. However, based on our data and the previous reports it seems that Nafion offers an insufficient steric and electrostatic stabilization effect and cannot prevent nanoparticle agglomeration at high metal loadings [48, 49]. 

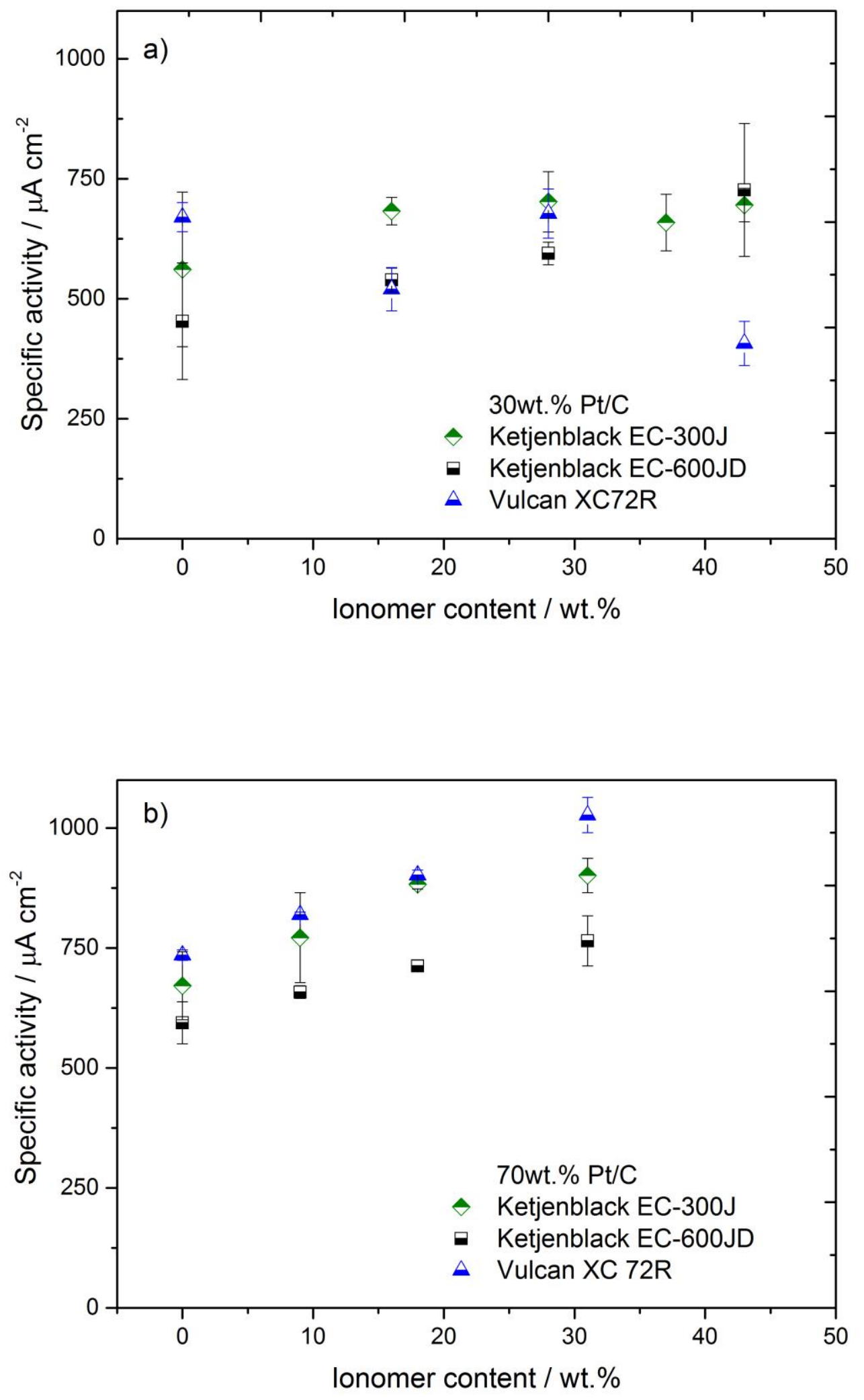
Fig. 4 Oxygen reduction activity expressed as specific activity (SA, $\left.\mu \mathrm{A} \mathrm{cm}{ }^{-2} \mathrm{Pt}\right)$ of a) $30 \mathrm{wt} . \%$ and b) $70 \mathrm{wt} . \%$ $\mathrm{Pt} / \mathrm{C}$ samples as a function of the ionomer content (in wt.\%). All SA are determined from the positive going scan at a potential of $0.9 \mathrm{~V}_{\mathrm{RHE}}$.

The electrocatalytic performance of the ionomer impregnated $\mathrm{Pt} / \mathrm{C}$ catalysts was determined using the thin film RDE methodology. In Figure 4 the SA of the ORR is summarized for the 30 and $70 \mathrm{wt} . \% \mathrm{Pt} / \mathrm{C}$ catalysts as function of the ionomer content in the catalyst layer. For the samples with 30 wt.\% Pt loading (Fig. 4A) the following picture evolves: using Ketjenblack as carbon support, in both cases (EC-300J and EC-600JD) the SA increases with increasing ionomer content in the catalyst layer. For the EC-600JD support the effect is more pronounced, i.e. a continuous increase in SA with increasing Nafion content is seen, whereas for the EC-300J support Nafion addition increases the SA, but no trend with increasing amount of Nafion is observed. Such an "initial" increase in ORR activity when adding ionomer to the catalyst layer most likely can be attributed to the fact that the ionomer impregnation results in a better distribution of the catalyst film on the GC electrode, see also discussion above. This phenomenon has been previously reported by Ke et al. [27] and would explain the observed effect. Also recently Shinozaki et al. reported an increase in SA for catalyst films of extremely low catalyst loading (amount of catalyst on GC electrode), i.e. below $5 \mathrm{~g}_{\mathrm{Pt}} \mathrm{cm}_{\text {geo }}^{-2}$ [42]. This is in contrast to older RDE measurements where no difference in SA was observed between loadings of 3.5 and $14 \mathrm{~g}_{\mathrm{Pt}} \mathrm{cm}_{\text {geo }}^{-2}$ [28]. An interesting difference, between both studies is however, that in the first case the catalyst films were dried in an atmosphere of isopropyl alcohol, whereas in the latter case - as in the study here an inert atmosphere of Ar was used.

For the sample using the Vulcan XC 72R support no clear trend evolves either. High ionomer content (>40 wt.\%) decreases the electrocatalytic activity for the ORR, indicating that excess Nafion may alter the diffusion of oxygen to the active sites. At least such an effect of Nafion 
is reported in previous work [50]. In order to probe this assumption, i.e. the inhibition of oxygen diffusion, we probed the diffusion limited current for Pt/Vulcan XC 72R samples containing 28 and 45 wt. \% Nafion, respectively (see Fig. 5). The result clearly demonstrates that while Nafion does not inhibit oxygen diffusion at low to moderate concentrations, excess in Nafion limits the oxygen mass transport to the active metal sites. This observation is also in agreement with [26], where it is reported that to avoid an influence of oxygen diffusion through a Nafion film placed on top of a Pt/C catalyst layer, a thickness of less than $0.1 \mu \mathrm{m}$ (corresponding to roughly $20 \mathrm{wt} . \%$ ) should be used.
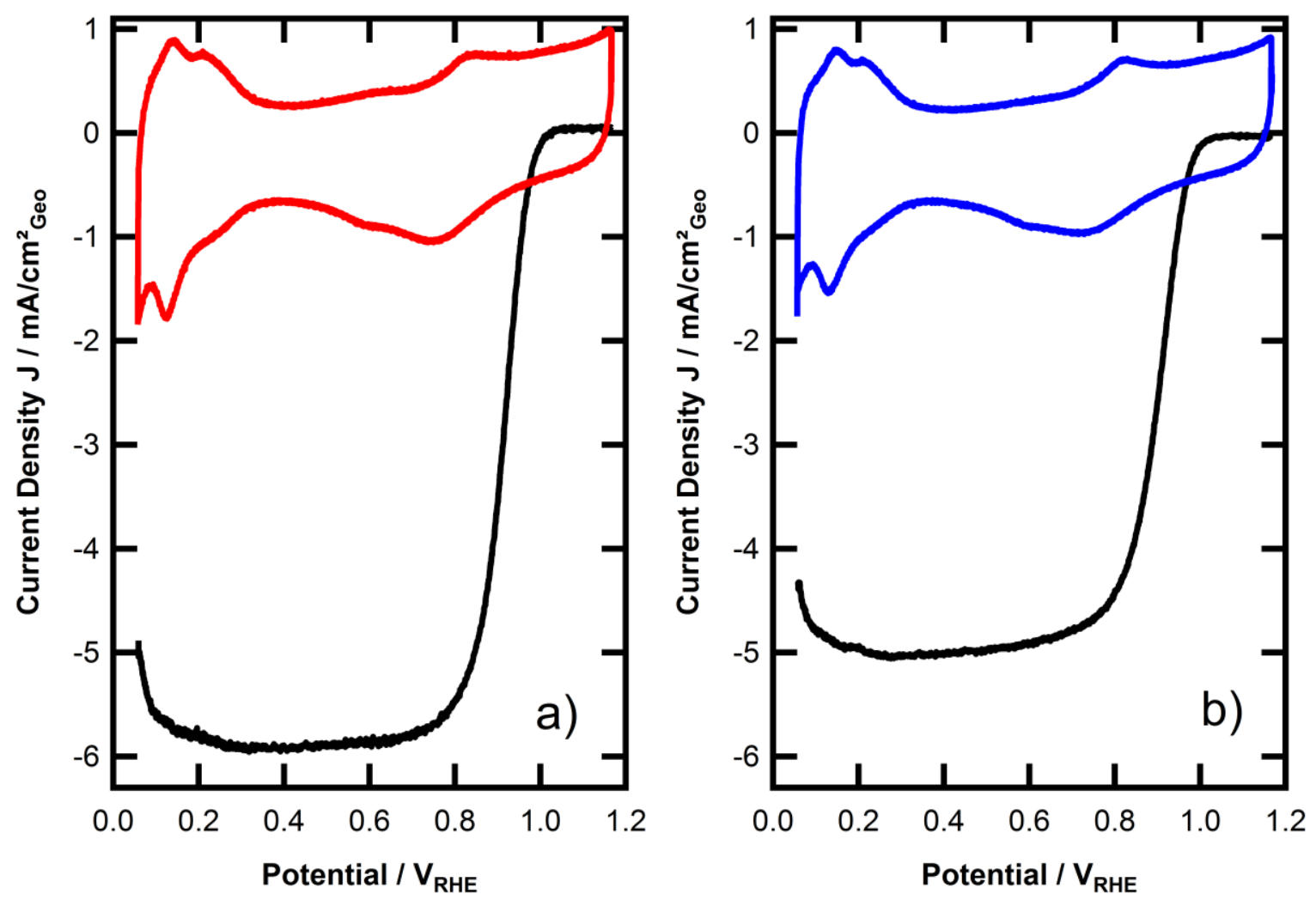

Fig. 5 Cyclic voltammograms and ORR RDE polarization curves of 30 wt.\% Pt/Vulcan XC 72R samples with a) 28 wt.\% (red) and b) 45 wt.\% (blue) Nafion ionomer in the catalyst layer.

By comparison, for the samples with $70 \mathrm{wt} . \%$ Pt loading again a clear trend evolves when impregnating the catalyst with Nafion ionomer (Fig. 4B). Even though the SA "start" (no 
ionomer) from higher values as compared to the corresponding $30 \mathrm{wt} \%$ samples, in each case the ORR SA improves by adding Nafion to the catalyst layer. The general trend in specific activity is $\mathrm{Pt} / \mathrm{EC} 600 \mathrm{JD}<\mathrm{Pt} / \mathrm{EC} 300 \mathrm{~J}<\mathrm{Pt} /$ Vulcan. It is noteworthy, that the catalyst samples impregnated with a higher amount of Nafion are the most active catalysts for ORR. For instance, for the $70 \mathrm{wt} . \% \mathrm{Pt} /$ Vulcan sample impregnation with $30 \mathrm{wt} . \%$ Nafion increases the ORR specific activity from 735 to $1030 \mu \mathrm{A} \mathrm{cm} \mathrm{cm}^{-1}$, which represents a $40 \%$ increase in apparent turnover rates. Comparing the SA of $10 \mathrm{wt} . \%$ Pt on Ketjenblack EC-300J with the 70wt.\% Pt Vulcan XC72R sample containing optimized Nafion content, even an improvement by a factor of three is reached.

\section{Conclusions}

To our knowledge, the present study is the first time it was systematically investigated by the thin film RDE methodology how the ionomer content in a catalyst influences Pt utilization and apparent catalytic performance as function of the $\mathrm{Pt}$ to carbon ratio. An essential prerequisite for the study was that Pt loading, Nafion content and carbon type could be controlled independent of each other by using a colloidal "tool-box synthesis" approach. It is demonstrated that an optimum performance requires a meticulous optimization for each specific catalyst (i.e. depending of Pt loading and support type). If such optimization is reached an apparent performance increase of ca. 50\% can easily obtained. Of specific interest is the observed increase in SA. We discussed the possible influence of the film properties on the performance. Alternatively, recently, Fortunelli et al. proposed that the ORR on Pt can be dramatically improved by tuning the solvent properties [51]. The authors link the performance to the polarizability of the interface. Although, we cannot determine the change in polarizability in our investigations, the interface in thin-film RDE measurements consists of Nafion and liquid electrolyte, the presented data demonstrate that fuel cell catalyst 
optimization needs to take the whole solid-electrolyte interface into account. More work needs to be done to investigate to what extend observed apparent performance increases can be utilized in fuel cells, i.e. MEAs, where no liquid electrolyte is present. The developed toolbox approach potentially can contribute to this important issue.

\section{Acknowledgements}

This work was supported by the Danish DFF through grant no.10-081337. We acknowledge

Dipl.-Ing. Andrea Mingers of the group of Dr. Karl J.J. Mayrhofer at the MPIE for the ICPMS analysis and Denis Okhrimenko from the Department of Chemistry, University of Copenhagen, for the BET measurements.

\section{References}

[1] E. Antolini, Review in Applied Electrochemistry. Number 54 Recent Developments in Polymer Electrolyte Fuel Cell Electrodes, Journal of Applied Electrochemistry, 34 (2004) 563-576.

[2] X. Zhao, W. Li, Y. Fu, A. Manthiram, Influence of ionomer content on the proton conduction and oxygen transport in the carbon-supported catalyst layers in DMFC, International Journal of Hydrogen Energy, 37 (2012) 9845-9852.

[3] J.M. Song, S.Y. Cha, W.M. Lee, Optimal composition of polymer electrolyte fuel cell electrodes determined by the AC impedance method, Journal of Power Sources, 94 (2001) 78-84.

[4] E. Antolini, L. Giorgi, A. Pozio, E. Passalacqua, Influence of Nafion loading in the catalyst layer of gas-diffusion electrodes for PEFC, Journal of Power Sources, 77 (1999) 136142.

[5] S.J. Lee, S. Mukerjee, J. McBreen, Y.W. Rho, Y.T. Kho, T.H. Lee, Effects of Nafion impregnation on performances of PEMFC electrodes, Electrochimica Acta, 43 (1998) 36933701 .

[6] E. Passalacqua, F. Lufrano, G. Squadrito, A. Patti, L. Giorgi, Nafion content in the catalyst layer of polymer electrolyte fuel cells: effects on structure and performance, Electrochimica Acta, 46 (2001) 799-805.

[7] G. Sasikumar, J.W. Ihm, H. Ryu, Optimum Nafion content in PEM fuel cell electrodes, Electrochimica Acta, 50 (2004) 601-605.

[8] H. Iden, A. Ohma, An in situ technique for analyzing ionomer coverage in catalyst layers, J Electroanal Chem, 693 (2013) 34-41.

[9] Z. Poltarzewski, P. Staiti, V. Alderucci, W. Wieczorek, N. Giordano, NAFION DISTRIBUTION IN GAS-DIFFUSION ELECTRODES FOR SOLID-POLYMERELECTROLYTE-FUEL-CELL APPLICATIONS, Journal of the Electrochemical Society, 139 (1992) 761-765. 
[10] P. Staiti, Z. Poltarzewski, V. Alderucci, G. Maggio, N. Giordano, SOLID POLYMER ELECTROLYTE FUEL-CELL (SPEFC) RESEARCH-AND-DEVELOPMENT AT THE INSTITUTE CNR-TAE OF MESSINA, International Journal of Hydrogen Energy, 19 (1994) 523-527.

[11] J. Xie, K.L. More, T.A. Zawodzinski, W.H. Smith, Porosimetry of MEAs Made by "Thin Film Decal" Method and Its Effect on Performance of PEFCs, Journal of the Electrochemical Society, 151 (2004) A1841-A1846.

[12] C.-Y. Ahn, J.-Y. Cheon, S.-H. Joo, J. Kim, Effects of ionomer content on Pt catalyst/ordered mesoporous carbon support in polymer electrolyte membrane fuel cells, Journal of Power Sources, 222 (2013) 477-482.

[13] V.A. Paganin, E.A. Ticianelli, E.R. Gonzalez, Development and electrochemical studies of gas diffusion electrodes for polymer electrolyte fuel cells, Journal of Applied Electrochemistry, 26 (1996) 297-304.

[14] J. Xie, F. Xu, D.L. Wood Iii, K.L. More, T.A. Zawodzinski, W.H. Smith, Influence of ionomer content on the structure and performance of PEFC membrane electrode assemblies, Electrochimica Acta, 55 (2010) 7404-7412.

[15] M. Uchida, Y. Aoyama, N. Eda, A. Ohta, Investigation of the Microstructure in the Catalyst Layer and Effects of Both Perfluorosulfonate Ionomer and PTFE-Loaded Carbon on the Catalyst Layer of Polymer Electrolyte Fuel Cells, Journal of the Electrochemical Society, 142 (1995) 4143-4149.

[16] K. Kodama, R. Jinnouchi, T. Suzuki, H. Murata, T. Hatanaka, Y. Morimoto, Increase in adsorptivity of sulfonate anions on Pt (111) surface with drying of ionomer, Electrochemistry Communications, 36 (2013) 26-28.

[17] T. Suzuki, K. Kudo, Y. Morimoto, Model for investigation of oxygen transport limitation in a polymer electrolyte fuel cell, Journal of Power Sources, 222 (2013) 379-389.

[18] J. Speder, L. Altmann, M. Roefzaad, M. Baumer, J.J.K. Kirkensgaard, K. Mortensen, M. Arenz, Pt based PEMFC catalysts prepared from colloidal particle suspensions - a toolbox for model studies, Physical Chemistry Chemical Physics, 15 (2013) 3602-3608.

[19] A. Zana, J. Speder, M. Roefzaad, L. Altmann, M. Baumer, M. Arenz, Probing Degradation by IL-TEM: The Influence of Stress Test Conditions on the Degradation Mechanism, Journal of the Electrochemical Society, 160 (2013) F608-F615.

[20] J. Speder, L. Altmann, M. Baumer, J.J.K. Kirkensgaard, K. Mortensen, M. Arenz, The particle proximity effect: from model to high surface area fuel cell catalysts, Rsc Advances, 4 (2014) 14971-14978.

[21] A. Zana, J. Speder, N.E.A. Reeler, T. Vosch, M. Arenz, Investigating the corrosion of high surface area carbons during start/stop fuel cell conditions: A Raman study, Electrochimica Acta, 114 (2013) 455-461.

[22] J. Speder, A. Zana, I. Spanos, J.J.K. Kirkensgaard, K. Mortensen, M. Hanzlik, M. Arenz, Comparative degradation study of carbon supported proton exchange membrane fuel cell electrocatalysts - The influence of the platinum to carbon ratio on the degradation rate, $\mathrm{J}$ Power Sources, 261 (2014) 14-22.

[23] Y. Wang, J.L. Zhang, X.D. Wang, J.W. Ren, B.J. Zuo, Y.Q. Tang, Metal nanoclusters stabilized with simple ions and solvents - promising building blocks for future catalysts, Top Catal, 35 (2005) 35-41.

[24] T.J. Schmidt, H.A. Gasteiger, G.D. Stäb, P.M. Urban, D.M. Kolb, R.J. Behm, Characterization of High-Surface-Area Electrocatalysts Using a Rotating Disk Electrode Configuration, Journal of the Electrochemical Society, 145 (1998) 2354-2358.

[25] U.A. Paulus, T.J. Schmidt, H.A. Gasteiger, R.J. Behm, Oxygen reduction on a highsurface area Pt/Vulcan carbon catalyst: A thin-film rotating ring-disk electrode study, Journal of Electroanalytical Chemistry, 495 (2001) 134-145. 
[26] E. Higuchi, H. Uchida, M. Watanabe, Effect of loading level in platinum-dispersed carbon black electrocatalysts on oxygen reduction activity evaluated by rotating disk electrode, Journal of Electroanalytical Chemistry, 583 (2005) 69-76.

[27] K. Ke, K. Hiroshima, Y. Kamitaka, T. Hatanaka, Y. Morimoto, An accurate evaluation for the activity of nano-sized electrocatalysts by a thin-film rotating disk electrode: Oxygen reduction on Pt/C, Electrochimica Acta, 72 (2012) 120-128.

[28] K.J.J. Mayrhofer, D. Strmcnik, B.B. Blizanac, V. Stamenkovic, M. Arenz, N.M. Markovic, Measurement of oxygen reduction activities via the rotating disc electrode method: From Pt model surfaces to carbon-supported high surface area catalysts, Electrochimica Acta, 53 (2008) 3181-3188.

[29] Y. Wang, J.W. Ren, K. Deng, L.L. Gui, Y.Q. Tang, Preparation of tractable platinum, rhodium, and ruthenium nanoclusters with small particle size in organic media, Chemistry of Materials, 12 (2000) 1622-1627.

[30] K.J.J. Mayrhofer, G.K.H. Wiberg, M. Arenz, Impact of glass corrosion on the electrocatalysis on Pt electrodes in alkaline electrolyte, Journal of the Electrochemical Society, 155 (2008) P1-P5.

[31] K.J.J. Mayrhofer, A.S. Crampton, G.K.H. Wiberg, M. Arenz, Analysis of the impact of individual glass constituents on electrocatalysis on pt electrodes in alkaline solution, Journal of the Electrochemical Society, 155 (2008) P78-P81.

[32] K.J.J. Mayrhofer, S.J. Ashton, J. Kreuzer, M. Arenz, An Electrochemical Cell Configuration Incorporating an Ion Conducting Membrane Separator between Reference and Working Electrode, International Journal of Electrochemical Science, 4 (2009) 1-8.

[33] H.A. Gasteiger, N. Markovic, P.N. Ross, E.J. Cairns, CO ELECTROOXIDATION ON WELL-CHARACTERIZED PT-RU ALLOYS, Journal of Physical Chemistry, 98 (1994) 617-625.

[34] K. Hartl, K.J.J. Mayrhofer, M. Lopez, D. Goia, M. Arenz, AuPt core-shell nanocatalysts with bulk Pt activity, Electrochemistry Communications, 12 (2010) 1487-1489.

[35] K. Shinozaki, J.W. Zack, R.M. Richards, B.S. Pivovar, S.S. Kocha, Oxygen Reduction Reaction Measurements on Platinum Electrocatalysts Utilizing Rotating Disk Electrode Technique: I. Impact of Impurities, Measurement Protocols and Applied Corrections, Journal of The Electrochemical Society, 162 (2015) F1144-F1158.

[36] S. Brunauer, P.H. Emmett, E. Teller, Adsorption of gases in multimolecular layers, Journal of the American Chemical Society, 1938, pp. 309-319.

[37] M. Uchida, Y. Aoyama, M. Tanabe, N. Yanagihara, N. Eda, A. Ohta, Influences of Both Carbon Supports and Heat-Treatment of Supported Catalyst on Electrochemical Oxidation of Methanol, Journal of the Electrochemical Society, 142 (1995) 2572-2576.

[38] M. Uchida, Y. Fukuoka, Y. Sugawara, N. Eda, A. Ohta, Effects of Microstructure of Carbon Support in the Catalyst Layer on the Performance of Polymer-Electrolyte Fuel Cells, Journal of the Electrochemical Society, 143 (1996) 2245-2252.

[39] M. Lee, M. Uchida, H. Yano, D.A. Tryk, H. Uchida, M. Watanabe, New evaluation method for the effectiveness of platinum/carbon electrocatalysts under operating conditions, Electrochimica Acta, 55 (2010) 8504-8512.

[40] T. Soboleva, X.S. Zhao, K. Mallek, Z. Xie, T. Navessin, S. Holdcroft, On the Micro-, Meso- and Macroporous Structures of Polymer Electrolyte Membrane Fuel Cell Catalyst Layers, Acs Appl Mater Inter, 2 (2010) 375-384.

[41] M. Nesselberger, M. Roefzaad, R. Faycal Hamou, P. Ulrich Biedermann, F.F. Schweinberger, S. Kunz, K. Schloegl, G.K.H. Wiberg, S. Ashton, U. Heiz, K.J.J. Mayrhofer, M. Arenz, The effect of particle proximity on the oxygen reduction rate of size-selected platinum clusters, Nature materials, 12 (2013) 919-924. 
[42] K. Shinozaki, B.S. Pivovar, S.S. Kocha, Enhanced Oxygen Reduction Activity on Pt/C for Nafion-free, Thin, Uniform Films in Rotating Disk Electrode Studies, ECS Transactions, 58 (2013) 15-26.

[43] S. Holdcroft, Fuel Cell Catalyst Layers: A Polymer Science Perspective, Chemistry of Materials, 26 (2014) 381-393.

[44] R. Subbaraman, D. Strmcnik, A.P. Paulikas, V.R. Stamenkovic, N.M. Markovic, Oxygen Reduction Reaction at Three-Phase Interfaces, ChemPhysChem, 11 (2010) 28252833.

[45] A. Ohma, K. Fushinobu, K. Okazaki, Influence of Nafion ${ }^{\circledR}$ film on oxygen reduction reaction and hydrogen peroxide formation on Pt electrode for proton exchange membrane fuel cell, Electrochimica Acta, 55 (2010) 8829-8838.

[46] J. Speder, A. Zana, I. Spanos, J.J.K. Kirkensgaard, K. Mortensen, M. Arenz, On the influence of the Pt to carbon ratio on the degradation of high surface area carbon supported PEM fuel cell electrocatalysts, Electrochemistry Communications, 34 (2013) 153-156.

[47] O.J. Curnick, B.G. Pollet, P.M. Mendes, Nafion (R)-stabilised Pt/C electrocatalysts with efficient catalyst layer ionomer distribution for proton exchange membrane fuel cells, Rsc Advances, 2 (2012) 8368-8374.

[48] Z. Liu, Z.Q. Tian, S.P. Jiang, Synthesis and characterization of Nafion-stabilized Pt nanoparticles for polymer electrolyte fuel cells, Electrochimica Acta, 52 (2006) 1213-1220.

[49] P.-C. Lee, D. Kim, T.-H. Han, S.-J. Kang, L. Pu, J.-D. Nam, B. Kim, J.-H. Lee, Synthesis of platinum nanoparticles using electrostatic stabilization and cluster duplication of perfluorinated ionomer, Macromol. Res., 17 (2009) 187-191.

[50] K. Kudo, T. Suzuki, Y. Morimoto, Analysis of Oxygen Dissolution Rate from Gas Phase into Nafion Surface and Development of an Agglomerate Model, ECS Transactions, 33 (2010) 1495-1502.

[51] A. Fortunelli, W.A. Goddard, Y. Sha, T.H. Yu, L. Sementa, G. Barcaro, O. Andreussi, Dramatic Increase in the Oxygen Reduction Reaction for Platinum Cathodes from Tuning the Solvent Dielectric Constant, Angewandte Chemie International Edition, 53 (2014) 66696672. 